\title{
Genetic heterogeneity in Rieger eye malformation
}

\author{
E Legius, C E M de Die-Smulders, F Verbraak, H Habex, R Decorte, P Marynen, \\ J P Fryns, J J Cassiman
}

\begin{abstract}
A three generation family with Rieger eye malformation sequence is described. No other abnormalities were present apart from the eye malformation. Linkage to EGF and D4S193 localised in 4q25 was excluded and this indicates that Rieger eye malformation is genetically different from typical Rieger syndrome with teeth and umbilical anomalies.
\end{abstract}

( 7 Med Genet 1994;31:340-341)

Department of Clinical Genetics, Maastricht, The Netherlands

CE M de Die-Smulders

Netherlands

Ophthalmic Research

Institute, Amsterdam,

The Netherlands

F Verbraak

Centre for Human

Genetics, University

of Leuven, Campus

Gasthuisberg, O\&N6,

Herestraat 49, B-3000

Leuven, Belgium

E Legius

H Habex

R Decorte

$P$ Marynen

J P Fryns

J J Cassiman Professor Cassiman.

Received 18 June 1993

Revised version accepted for publication 13 October 1993

Rieger syndrome (RS) is an autosomal dominant disorder affecting cleavage of the anterior segment of the eye (Rieger eye malformation sequence) as well as the development of teeth and midfacial structures. ${ }^{1}$ This results in iris hypoplasia, strands running from the iris to the posterior surface of the cornea, posterior embryotoxon, glaucoma in $50 \%$ of patients, hypodontia, abnormal teeth, and midfacial hypoplasia. Redundant periumbilical skin is also an important feature.

Until recently the chromosomal localisation of RS was uncertain. Probable linkage of anterior segment mesenchymal dysgenesis to the MNS blood group on $4 \mathrm{q}$ has been reported. ${ }^{2}$ Five patients with small deletions in the $4 \mathrm{q} 23-26$ region and Rieger syndrome have been identified, ${ }^{3-7}$ and more recently definite linkage to markers from the same chromosomal region was reported in three Rieger syndrome families. ${ }^{8}$ A maximum lod score of $4 \cdot 36$
Correspondence to

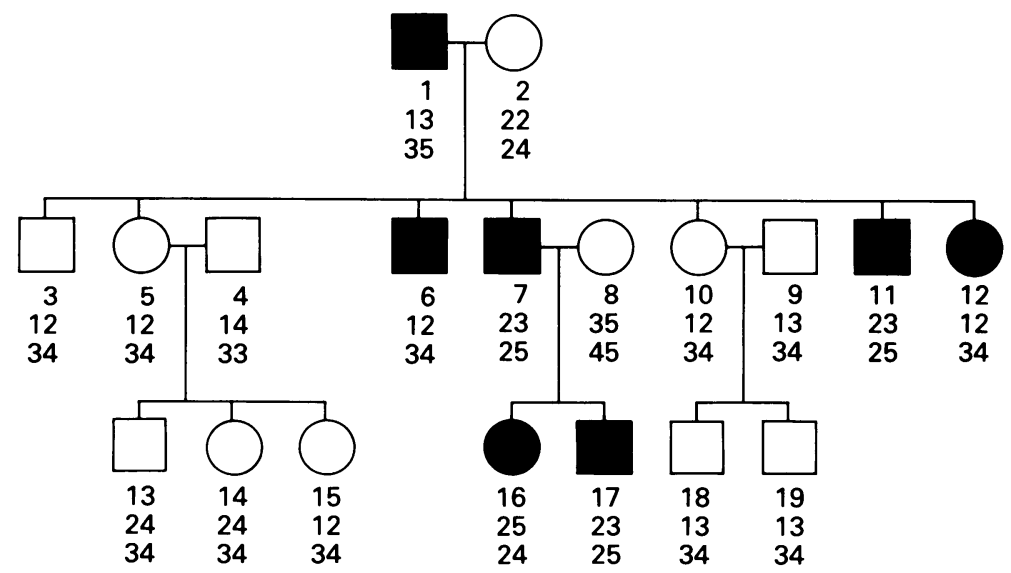

Pedigree of the three generation family with Rieger eye malformation syndrome. The upper marker underneath each subject represents the tetranucleotide repeat polymorphism in EGF, the lower marker is a dinucleotide repeat at D4S193. For each short tandem repeat one of the PCR primers was conjugated with fluorescein isothiocyanate (FITC), and PCR fragments were separated by electrophoresis on an automated sequencing device (ALF Pharmacia). was obtained for $\mathrm{D} 4 \mathrm{~S} 193$ at $0 \%$ recombination. RS has also been linked to the epidermal growth factor (EGF) locus, and although a recombinant was identified EGF remains a candidate gene for RS.

In an attempt to confirm these linkage data we performed molecular studies on 19 members of a three generation Dutch family (figure) with typical Rieger eye malformation sequence, hypertelorism, and maxillary hypoplasia. All members were carefully examined clinically and ophthalmologically. Anomalies of the anterior chamber of the eye were present in all patients. Expression was variable, ranging from iris hypoplasia, iris strands, and uncomplicated glaucoma arising at adult age to congenital buphthalmos. No teeth anomalies or umbilical changes were present in affected persons.

Using the polymerase chain reaction (PCR), two short tandem repeat polymorphisms on chromosome 4q, EGF ${ }^{8}$ and $\mathrm{D} 4 \mathrm{~S} 193,{ }^{9}$ were amplified from genomic DNA. The results are summarised in the figure. It is clear from these data that neither of the two markers segregate with the disease in this large family.

Statistical analysis of the data is shown in the table, and a region of $9 \mathrm{cM}$ was identified on both sides of each of the two markers with a lod score lower than -2 , excluding linkage to this region in this family. Lowering the value of the penetrance only extended the region with a two point lod score lower than -2 . These data exclude linkage to the same region that showed strong linkage to RS in previously reported families. This may indicate that Rieger eye malformation with maxillary hypoplasia and hypertelorism but without teeth or umbilical anomalies is genetically different from typical RS with hypodontia or umbilical abnormalities or both. Heterogeneity in this type of eye malformation has to be taken into account in genetic counselling, especially if definite linkage to markers on $4 \mathrm{q}$ cannot be established within the family examined.

Various other chromosomal abnormalities have been reported in association with a Rieger-type of eye anomaly ${ }^{1314}$ and are candidate regions for other forms of dominantly inherited Rieger eye malformation sequences, with or without hypodontia.

This investigation was supported by a grant "Geconcerteerde Acties - Ministerie voor Onderwijs" from the Belgian GovernActies - Ministerie voor Onderwijs" from the Belgian Government and by a grant from the 1nteruniversity Network for Fundamental Research (IUAP, 1991-1995) from the Belgian "Nationa Fonds vor Wer

1 Jorgenson RJ, Levin LS, Cross HE, Yoder F, Kelly TE. The Rieger syndrome. Am 7 Med Genet 1978;2:307-18. 2 Ferrell RE, Hittner HM, Kretzer FL, Antoszyk JH. Anterior segment mesenchymal dysgenesis: probable linkage to 
Two point lod scores between RS and EGF and D4S193 at different recombination fractions. Data were analysed using MLINK from the LINKAGE package, ${ }^{10}$ with a penetrance of 1 for $R S$. Since all subjects in this three generation family were completely typed we could assume the same allele frequency for the different alleles ${ }^{112}$ (an exact allele frequency for these markers is not available). Linkage of $R S$ to each of the two short tandem repeat markers is excluded, but on the other hand both markers segregated perfectly with each other, and a maximum two point lod score of 3.9 was obtained between EGF and D4S193 at 0 recombination.

\begin{tabular}{lrrrrrrrr}
\hline$\theta$ & 0.010 & 0.020 & 0.030 & 0.040 & 0.050 & 0.060 & 0.070 & 0.080 \\
\hline EGF & -5.614 & -4.431 & -3.749 & -3.272 & -2.907 & -2.613 & -2.369 & -2.160 \\
D4S193 & -5.614 & -4.431 & -3.749 & -3.272 & -2.907 & -2.613 & -2.369 & -2.160 \\
\hline
\end{tabular}

the MNS bloodgroup on chromosome 4. Am $\mathcal{F}$ Hum Genet 1982;34:245-9.

3 Ligutic I, Brecevic L, Petkovic I, Kalogjera T, Rajic Z. Interstitial deletion $4 \mathrm{q}$ and Rieger syndrome. Clin Genet $1981 ; 20: 323-7$.

4 Serville F, Broustet A. A pericentric inversion and partial monosomy $4 \mathrm{q}$ associated with congenital anomalies. Hum Genet 1977;399:239-42.

5 Mitchell JA. Deletions of different segments of the long arm of chromosome 4. Am f Med Genet 1981;8:73-90.

6 Vaux C, Sheffield L, Keith CG, Voullaire L. Evidence that Rieger syndrome maps to $4 \mathrm{q} 25$ or $4 \mathrm{q} 27$. $\mathcal{F}$ Med Genet Rieger syndrom

7 Fryns JP, Van den Berghe H. Rieger syndrome and interstitial 4q26 deletion. Genetic Counselling 1992;3:153-4.

8 Murray JC, Bennet SR, Kwitek AE, et al. Linkage of Rieger syndrome to the region of the epidermal growth factor gene on chromosome 4. Nature Genet 1992;2:46-9.
9 Mills KA, Buetow KH, Xu Y, et al. Genetic and physical maps of human chromosome 4 based on dinucleotide repeats. Genomics 1992;14:209-19.

10 Lathrop M, Lalouel JM, Julier C, Ott J. Multilocus linkage analysis in humans: detection of linkage and estimation of recombination. Am $\mathcal{J}$ Hum Genet 1985;37:482-98.

11 Freimer NB, Sandkuijl LA, Blower SM. Incorrect specification of marker allele frequencies: effects on linkage analysis. Am f Hum Genet 1993;52:1102-10.

12 Ott J. Strategies for characterizing highly polymorphic markers in human gene mapping. Am $\mathcal{f}$ Hum Genet 1992;51:283-90.

13 Nielsen F, Tranebjaerg L. A case of partial monosomy 21 q22.2 associated with Rieger's syndrome. $\mathcal{F}$ Med Genet 21q22.2 associat

14 Stathacopoulos RA, Bateman JB, Sparkes RS, Hepler RS. The Rieger syndrome and a chromosome 13 deletion. $f$ Pediatr Ophthalmol Strabismus 1987;24:198-203. 